\title{
Predicting occupational asthma and rhinitis in bakery workers referred for clinical evaluation
}

\author{
Badri Sadat Jonaid, ${ }^{1,2}$ Jos Rooyackers, ${ }^{1,3}$ Erik Stigter, $^{3}$ Lützen Portengen, ${ }^{1}$ \\ Esmeralda Krop, ${ }^{1}$ Dick Heederik'
}

- Additional material is published online only. To view please visit the journal online (http://dx.doi.org/10.1136/ oemed-2016-103934).

'Division of Environmental Epidemiology, Institute for Risk Assessment Sciences (IRAS), Utrecht University, Utrecht, The Netherlands

${ }^{2}$ Arak University of Medical Sciences, Arak, Iran

${ }^{3}$ Netherlands Expertise Center for Occupational Respiratory Disorders, Division Heart and Lungs, University Medical Centre, Utrecht, The Netherlands

Correspondence to Badri Sadat Jonaid, Division of Environmental Epidemiology, Institute for Risk Assessment Sciences (IRAS), Utrecht University, P.O. Box 80178, 3508 TD Utrecht, The Netherlands; B.S.Jonaid@uu.nl

Received 27 June 2016 Revised 17 January 2017 Accepted 30 January 2017 Published Online First 17 March 2017

\section{ABSTRACT}

Background Occupational allergic diseases are a majo problem in some workplaces like in the baking industry. Diagnostic rules have been used in surveillance but not yet in the occupational respiratory clinic.

Objective To develop diagnostic models predicting baker's asthma and rhinitis among bakery workers at high risk of sensitisation to bakery allergens referred to a specialised clinic.

Methods As part of a medical surveillance programme, clinical evaluation was performed on 436 referred Dutch bakery workers at high risk for sensitisation to bakery allergens. Multivariable logistic regression analyses were developed to identify the predictors of onset of baker's asthma and rhinitis using a self-administered questionnaire and compared using a structured medical history. Performance of models was assessed by discrimination (area under the receiver operating characteristics curve) and calibration (Hosmer-Lemeshow test). Internal validity of the models was assessed by a bootstrapping procedure.

Results The prediction models included the predictors of work-related upper and lower respiratory symptoms, the presence of allergy and allergic symptoms, use of medication (last year), type of job, type of shift and working years with symptoms ( $\geq 10$ years). The developed models derived from both self-administered questionnaire and the medical history showed a relatively good discrimination and calibration. The internal validity showed that the models developed had satisfactory discrimination. To improve calibrations of models, shrinkage factors were applied to model coefficients. Conclusion The probability of allergic asthma and rhinitis in referred bakers could be estimated by diagnostic models based on both a self-administered questionnaire and by taking a structured medical history.

\section{INTRODUCTION}

Occupational exposure to high molecular weight (HMW) flour allergens (wheat, rye, barley) and enzymes ( $\alpha$-amylase) is documented as a major cause of sensitisation among bakery workers, ${ }^{1} 2$ with a yearly incidence between 1 and 10 cases per 1000 workers. $^{2}$ An elevated risk of sensitisation has shown to be present even at relatively low exposure levels. ${ }^{3}$ Any worker sensitised to bakery allergens may develop allergic symptoms. ${ }^{245}$ Specific immunoglobulin $\mathrm{E}$ (IgE) responses to inhalation of flour allergens have been reported in approximately $60 \%$ of bakery workers with work-related respiratory symptoms. ${ }^{6}$ Sensitisation to wheat flour allergens is well
What this paper adds

- The probability of onset of baker's asthma and rhinitis in workers at risk of being sensitised can be estimated using the developed models derived from both self-administered questionnaire and the medical history taken by a physician.

- The self-administered questionnaire models can be used to select bakers for further clinical evaluations.

- The developed diagnostic prediction models consist of a limited set of predictors for both baker's asthma and rhinitis.

recognised as a risk factor for allergic occupational asthma and rhinitis among bakery workers. ${ }^{78}$ In addition, symptoms of allergic occupational rhinitis often precede the onset of allergic occupational asthma. ${ }^{8}$ Medical surveillance programmes aimed at early detection and diagnosis of allergic occupational asthma and rhinitis in exposed bakery workers may encourage the implementation of exposure measures, prevent workers from leaving their jobs and reduce the incidence of allergic occupational asthma and hence the disease burden. ${ }^{5-12}$ Since the feasibility and cost-effectiveness of medical investigation of all bakery workers are limited, we developed a questionnaire-based prediction model to estimate the individual probability of sensitisation to bakery allergens. ${ }^{13}$ This prediction model enables risk stratification of bakery workers into low-risk, intermediate-risk and high-risk groups, and is now applied in a nationwide medical surveillance programme in the Netherlands. Meijer et al ${ }^{10}$ showed the usefulness of the stratification procedure to detect work-related allergy among bakery workers and described the overall surveillance strategy. ${ }^{12}$ Workers at increased risk of sensitisation were referred to a specialised clinic for additional clinical investigations. ${ }^{13}$ The initial diagnostic rule aimed at the prediction of sensitisation to bakery allergens. The current study focuses on two clinical entities, work-related allergic asthma and rhinitis, in bakery workers referred to a specialised clinic. Development of a prediction model for occupational allergy may further improve the selection of exposed workers for clinical evaluation.

We explored whether it is possible to construct simple diagnostic models predicting the individual probability of onset of baker's asthma (BA) and baker's rhinitis (BR) among bakery workers referred
Rooyackers J, Stigter E,

et al. Occup Environ Med 2017:74:564-572. 
to a specialised clinic using a self-administered questionnaire and the medical history provided by a physician.

\section{MATERIALS AND METHODS}

\section{Study design and population}

On behalf of the branch of industrial and traditional bakeries in the Netherlands, a continuous medical surveillance programme has been running since 2010. For the present study, baseline data collected between June 2010 and March 2014 were used to develop simple diagnostic prediction models for early detection of BA and BR as outcomes. Of 7099 bakery workers who were recruited, 4351 workers (participation rate of $65 \%$ ) completed a short self-administered questionnaire, including 3080 and 1271 workers, respectively, from traditional and industrial bakeries. Using a questionnaire-based diagnostic model, sensitisation to bakery allergens (wheat, rye and $\alpha$-amylase) was predicted and bakers were stratified into low-risk, intermediate-risk and highrisk groups. ${ }^{13}$ This study started with a subset of data consisting of 436/1909 (23\%) participants (see online supplementary figure S1) from the intermediate-risk or high-risk groups, in whom medical evaluation was performed after referral to a specialised clinic. All subjects gave informed consent.

\section{Medical history}

All referred bakers were subjected to a clinical investigation by a pulmonologist and an occupational physician specialised in diagnosing occupational respiratory disease. They used a prestructured medical history composed of 33 questions about allergic symptoms of the nose and the eyes, lung symptoms, asthma attack, allergic symptoms to common allergens and symptoms after exposure to non-specific stimuli such as fog and changes in temperature. We identified two clusters of correlated symptoms, including 'rhinoconjunctivitis' and 'work-related upper respiratory symptoms'. Rhinoconjunctivitis was defined as any experience of itchy/watery and/or red eyes and/or itchy/runny nose and/or sneezing. 'Work-related upper respiratory symptoms' was defined as the presence of itchy/watery eyes and/or itchy/runny nose and/or sneezing during work that improved away from work. Latency period was defined as the duration between the start of exposure to bakery allergens and the onset of respiratory symptoms.

The medical history was supplemented with some general questions such as medical and family history of asthma and nasal allergy (hay fever), individual history of work (eg, job title, number of years worked, job absenteeism and change in job due to allergic symptoms), smoking habits, use of medication for respiratory problems and visiting a physician for allergic symptoms. Job absenteeism was defined as taking sick leave due to allergic symptoms in the last year. Current smokers were defined as presently smoking or smoking in the last month.

The questionnaire item 'allergy to any substance' was defined as any experience of hypersensitivity or allergy to any substance (single or multiple) inducing an allergic response.

\section{Serum total and specific IgE tests}

Serum total IgE was measured with a sandwich enzyme immunoassay (EIA), calibrated with commercially available IgE standards. ${ }^{14}$ Elevated total IgE was defined as $\geq 100 \mathrm{kU} / \mathrm{L}$. Specific IgE to common allergens (house dustmite (HDM), grass pollen, birch pollen, cat and dog) was quantified using a previously developed EIA as described elsewhere. ${ }^{14}$ Specific IgE antibodies against wheat, rye and $\alpha$-amylase were measured with an earlier developed and modified EIA. ${ }^{14}$ The final optical density (OD) was double-corrected for the serum and the reagent blanks. OD exceeding +0.1 of the reagent blank was considered positive. Atopy was defined as the presence of specific IgE to at least one of the common allergens tested.

\section{Lung function tests}

Spirometry was performed according to the American Thoracic Society/European Respiratory Society standards. ${ }^{15}$ Normal values were derived from Quanjer et al. ${ }^{16}$ In the case of moderate or severe airway obstruction (forced expiratory volume in $1 \mathrm{~s}\left(\mathrm{FEV}_{1}\right)<50 \%$ predicted), reversibility was tested, and treatment for asthma or chronic obstructive pulmonary disease was started or optimised. Evaluation of work-related asthma was postponed until the clinical course and medication was stable for at least 6 weeks.

Non-specific bronchial hyper-responsiveness (NSBHR) was assessed by methacholine challenge test according to the American Thoracic Society guidelines. ${ }^{17}$ The test was carried out based on the five-breath dosimeter technique using the Aerosol provocation system with a DeVilbiss model 646 nebulizer (Zan, Oberthulpa, Germany). Airway hyper-responsiveness $\left(\mathrm{BHR}_{20}\right)$ was defined as a provocative dose of methacholine causing a $20 \%$ drop in $\mathrm{FEV}_{1}\left(\mathrm{PD}_{20}\right)$ of $1.92 \mathrm{mg}$ or less.

In workers with work-related asthma symptoms and positive NSBHR while at work or with persistent airway obstruction, serial peak expiratory flow (SPEF) measurements were carried out with a minimum of four times a day and for at least 2 weeks both at and off work. ${ }^{11} 18$ A difference of $>20 \%$ in the mean peak expiratory flow rate or amplitudes between recordings at and off work was considered a work-related pattern. ${ }^{18}$ In addition, methacholine challenge test was repeated after 2 weeks away from work. A change of at least one doubling dose increase in $\mathrm{PD}_{20}$ was regarded as significant.

\section{Baker's asthma and rhinitis}

Medical diagnoses of BA and BR were considered as clinical outcomes. BA was defined on the presence of the following criteria: (1) diagnosis of asthma and/or work-related asthma symptoms, (2) work-related pattern in SPEF or change in NSBHR and (3) sensitisation to at least one of the bakery allergens. ${ }^{1118}$ A diagnosis of BA was excluded if there were no indications of asthma symptoms and a worker showed no positive NSBHR within 24 hours after exposure while working uninterrupted for 2 weeks. BR was defined as the presence of nasal symptoms while at work and sensitisation to at least one of the bakery allergens tested. ${ }^{8}$

\section{Statistical analysis}

Descriptive statistics and the statistical analyses to develop the diagnostic predictive models in the development set were performed using SAS V.9.4. Internal validity using bootstrapping procedure was conducted in R (V.3.3) using the RMS library (5.0). Cut-off values were selected on the basis of the statistical distributions of numeric variables. Multiple imputation approach was performed for variables with a distribution of missing values from one and more to yield valid and unbiased results. In multivariable prediction research, multiple imputation methods are known to be superior to single imputation techniques. ${ }^{19}$ Of the variables with missing values included in the model development, 15 variables had 1-8 missing values, and 7 had 11-26.

\section{Model development and internal validation}

Separate diagnostic prediction models, consisting of the self-administered questionnaire model only and the medical history model only, were constructed for each diagnosed outcome 
including BA and BR. At first, the most relevant variables from the self-administered questionnaire and also from the medical history as potential predictors relating to the diagnosed BA and BR were separately entered in the univariate logistic regression analyses. We kept only the candidate predictors that were associated with diagnosed BA or BR and if they met a statistical significance of $\mathrm{p}<0.1$. Then, multivariable backward logistic regression analyses were applied to select the significant potential predictors of BA and BR. At the end, the significant $(\mathrm{p}<0.05)$ predictors of BA and BR were retained in the final models. ORs with 95\% CI were also calculated for all selected predictors included in the diagnostic prediction models. A bootstrapping resampling procedure was performed to validate the developed models internally. A receiver operating characteristic (ROC) area adjusted for model optimism and a shrinkage factor to adjust models for overfitting were obtained from this procedure. ${ }^{20}$ Regression coefficients of predictors from the developed models were subsequently multiplied by the shrinkage factor to alleviate the optimistic predictions when the model is applied in an independent sample of workers. ${ }^{21}$

\section{Model performance and updating}

The performance of models was assessed by evaluating discrimination and calibration. Discrimination defines the ability of the model to correctly differentiate between individuals with and without the outcome or disease, and was measured by the area under the ROC curve. The area under the curve (AUC) ranges from 0 to 1 , with a value of 0.5 representing 'no discrimination' and 1 indicating 'excellent discrimination'. ${ }^{22}$ In general, the best cut-point is in the closest upper left corner of the ROC curve, where sensitivity is high and 1 - specificity (the false-positive rate) is low. Therefore, this probability threshold was used to assess the accuracy of the diagnostic prediction models by computing the true positive (as sensitivity) and negative (as specificity) rates, and positive and negative predictive values. When the outcomes are binary, the discriminatory power of a predictive model is also measured by the concordance (c) statistic which is identical to the ROC area. ${ }^{23} \mathrm{We}$ determined the c-statistic for all of the models in the validation set. Calibration refers to the agreement between the predicted probability and observed prevalence of an outcome and was assessed by the Hosmer-Lemeshow (HL) 'goodness-of-fit' test. ${ }^{22}$ The relations between the predicted probabilities and the observed frequencies of the outcomes were assessed graphically in the validation set by plotting the predicted probabilities on $\mathrm{x}$-axis against the observed prevalence on y-axis. ${ }^{22}$ The agreement between the predicted probabilities and the observed frequencies can be visualised by a line which can be characterised by a calibration slope and an intercept. A perfect calibration is defined with an intercept of 0 indicating that the mean predicted probability is equal to the mean observed frequency, and a slope equal to 1 indicating that the plot of calibration lies entirely on the $45^{\circ}$ line.

The authors updated the developed models to improve the performance and to avoid overfitting by applying the correction factors obtained from the validation set to the intercept and the regression coefficients of the predictors in the developed models to be presented in the final models.

\section{RESULTS}

\section{General and health characteristics}

The study population was restricted to 421 workers, and 15 were excluded as medical evaluation in none of these bakers was complete. Table 1 presents the general characteristics of the study population stratified into high-risk (71.5\%) and intermediate-risk $(28.5 \%)$ groups for sensitisation. The population was predominantly male (93.6\%). Current smokers were more frequent in the intermediate-risk group. Workers in the high-risk group more frequently reported job change $(p=0.03)$ and job absenteeism $(\mathrm{p}=0.04)$. BA and BR were diagnosed in $28(6.5 \%)$ and $192(54.4 \%)$ workers, respectively. In the highrisk group, $92.9 \%$ of the workers had BA and $82 \%$ had BR. Workers with BA and BR in the high-risk group more frequently worked as bread bakers in a traditional bakery and in one shift. These workers also more frequently reported job absenteeism and change of job, percentages being considerably higher as compared with workers in the whole study population.

Health characteristics obtained by both self-administered questionnaire and the medical history taken by a physician, across different risk groups are presented in table 2. Overall, the prevalence of various symptoms was relatively high in both self-administered questionnaire and medical history taken by a physician. Moreover, observed symptoms were reported more frequently in the high-risk group. Within the high-risk group, all symptoms except rhinitis and allergic symptoms were reported more frequently in workers with BA than in workers with BR. As expected, workers with diagnosed $\mathrm{BA}$ and $\mathrm{BR}$ were more often atopic and sensitised (see online supplementary table S2). Of 28 workers with BA, 27 (96\%) also had BR, indicating a strong association between these two outcomes $(p=0.0002)$.

\section{Prediction of BA and BR using self-administered questionnaire}

Model development, validation and updating

Table 3 presents the results of univariate associations between diagnosed BA and BR and the candidate predictors obtained from a self-administered questionnaire. After entering all 12 candidate predictors in a multivariable logistic regression analysis using a backward selection, 3 predictors remained with significant contributions $(\mathrm{p}<0.05)$ to the risk prediction of BA (work-related lower respiratory symptoms, work-related conjunctivitis and use of medication in the last year). The final model was obtained after the internally validated and adjusted model in the development set. The model showed good discrimination, with an ROC area of 0.87 after internal validation $(95 \%$ CI, 0.81 to 0.89 ), suggesting a good differentiation between workers with and without diagnosed BA (table 3). This result showed that the optimism was very small with an AUC difference of 0.002. Calibration of the model (HL test) in the development set was 0.94 . Calibration of the model in the validation set is given in figure 1A. The calibration slope of non-parametric line was smaller than $1(0.79$ (95\% CI, 0.60 to 1.06$))$, which is reflecting an overfitting of the model in the development set. The shrinkage factor of 0.79 obtained from the bootstrapping was applied to the intercept and the regression coefficients of the predictors in the final model.

The accuracy of the model was estimated as a sensitivity of $98 \%-100 \%$, specificity of $99 \%-100 \%$, positive predictive value (PPV) of $32 \%-41 \%$ and negative predictive value (NPV) of $60 \%-68 \%$ based on a selected outpoint of $\geq 0.14$ as the desirable probability threshold obtained by ROC curve.

The developed questionnaire model predicting $\mathrm{BR}$ including five selected significant predictors $(p<0.05)$ is shown in table 3 . The selected predictor 'type of job' is composed of five different jobs, namely bread baking, confectionery, bread and confectionery, work at the test bakery and preparing dough. The first four types of jobs were significantly associated with OR. The discrimination of the model after bootstrapping was fair (ROC 
Table 1 The general characteristics of the bakery workers identified by a questionnaire-based prediction model as intermediate-risk or high-risk groups for sensitisation to bakery allergens and workers with diagnosed baker's asthma and rhinitis in a clinic

\begin{tabular}{|c|c|c|c|c|c|c|c|}
\hline & \multirow[b]{3}{*}{$\begin{array}{l}\text { Total } \\
(n=421)\end{array}$} & \multirow{2}{*}{\multicolumn{2}{|c|}{$\begin{array}{l}\text { Identified risk groups for } \\
\text { sensitisation }\end{array}$}} & \multirow{2}{*}{\multicolumn{2}{|c|}{$\begin{array}{l}\text { Baker's asthma ( } n=28,6.5 \%) \\
\text { Identified risk groups for } \\
\text { sensitisation }\end{array}$}} & \multirow{2}{*}{\multicolumn{2}{|c|}{$\begin{array}{l}\text { Baker's rhinitis ( } n=192,54.4 \% \text { ) } \\
\text { Identified risk groups for } \\
\text { sensitisation }\end{array}$}} \\
\hline & & & & & & & \\
\hline & & $\begin{array}{l}\text { High } \\
(\mathrm{n}=301)\end{array}$ & $\begin{array}{l}\text { Intermediate } \\
(n=120)\end{array}$ & $\begin{array}{l}\text { High } \\
(n=26)\end{array}$ & $\begin{array}{l}\text { Intermediate } \\
(n=2)\end{array}$ & $\begin{array}{l}\text { High } \\
(n=154)\end{array}$ & $\begin{array}{l}\text { Intermediate } \\
(\mathrm{n}=38)\end{array}$ \\
\hline Age, AM (SD) & $41.0(10.9)$ & $41.0(10.7)$ & $41.1(11.3)$ & $40.8(12.0)$ & $53.7(10.4)$ & $40.7(10.3)$ & $38.9(10.5)$ \\
\hline \multicolumn{8}{|l|}{ Gender } \\
\hline Male & 394 (93.6) & $276(91.7)$ & $118(98.3)$ & $25(96.2)$ & $2(100)$ & $141(91.6)$ & $38(100)$ \\
\hline Female & $27(6.4)$ & $25(8.3)$ & $2(1.7)$ & $1(3.9)$ & - & $13(8.4)$ & - \\
\hline Current smoker & $104(25)$ & $62(21)^{*}$ & $42(35.3)$ & $7(26.9)$ & $1(50)$ & $33(21.6)$ & $10(27)$ \\
\hline \multicolumn{8}{|l|}{ Work history } \\
\hline Years of work, AM (SD) & $21.4(11.1)$ & $21.1(11.0)$ & $22.0(11.6)$ & $22.2(10.4)$ & $31.0(0)$ & $21.9(10.3)$ & $21.5(11.3)$ \\
\hline Change of job & $37(8.8)$ & $30(10.0) \dagger$ & $7(5.8)$ & $4(15.4)$ & $1(50)$ & $18(11.7)$ & $3(7.9)$ \\
\hline Job absenteeism (last year) & $38(6.1)$ & $33(11.1) \ddagger$ & $5(4.2)$ & $6(23.0)$ & - & $19(12.3)$ & $1(2.6)$ \\
\hline \multicolumn{8}{|l|}{ Type of bakery } \\
\hline Traditional & $255(60.6)$ & $190(63.0)$ & $65(54.2)$ & $18(69.2)$ & $1(50)$ & $107(69.5)$ & $24(63.2)$ \\
\hline Industrial & $166(39.4)$ & $111(37.0)$ & $55(45.8)$ & $8(30.8)$ & $1(50)$ & $47(30.5)$ & $14(38.8)$ \\
\hline \multicolumn{8}{|l|}{ Type of job } \\
\hline Bread baking & $152(36.1)$ & $109(36.2)$ & $43(35.8)$ & $12(43.0)$ & - & $63(40.9)$ & $13(34.2)$ \\
\hline Confectionery & $69(16.4)$ & $51(16.9)$ & $18(15.0)$ & $2(7.7)$ & - & $29(18.8)$ & $7(18.4)$ \\
\hline Bread and confectionery baking & $84(20.0)$ & $63(20.9)$ & $21(17.5)$ & $8(30.8)$ & $1(50)$ & $37(24.0)$ & $9(23.7)$ \\
\hline Preparing dough & $38(9.0)$ & $23(7.6)$ & $15(12.5)$ & $2(7.7)$ & $1(50)$ & $11(7.1)$ & $5(13.2)$ \\
\hline Work at test bakery & $3(0.7)$ & $2(0.7)$ & $1(1.0)$ & - & - & - & \\
\hline Storage work & $11(2.6)$ & $7(2.3)$ & $4(3.1)$ & - & - & $2(1.3)$ & $1(2.6)$ \\
\hline Maintenance work & $9(2.1)$ & $8(2.7)$ & $1(1.0)$ & - & - & $1(0.7)$ & $1(2.6)$ \\
\hline Cleaning work & $3(0.7)$ & $2(0.7)$ & $1(1.0)$ & - & - & $1(0.7)$ & - \\
\hline Other works & $52(12.4)$ & $36(12.0)$ & $16(13.1)$ & $2(7.7)$ & - & $10(6.5)$ & $2(5.3)$ \\
\hline \multicolumn{8}{|l|}{ Type of shift } \\
\hline One-shift work & $237(56.3)$ & $180(59.8)$ & $57(47.5)$ & $20(76.9)$ & $1(50)$ & $100(66.8)$ & $22(59.5)$ \\
\hline Two-shift work & $65(15.4)$ & $43(14.3)$ & $22(18.3)$ & $1(3.9)$ & $1(50)$ & $20(13.2)$ & $6(16.2)$ \\
\hline Three-shift work & $119(28.3)$ & $78(25.9)$ & $41(34.2)$ & $5(19.2)$ & - & $32(21.0)$ & $9(24.3)$ \\
\hline
\end{tabular}

Data presented as $\mathrm{n}(\%)$ unless otherwise stated; high-risk versus intermediate-risk group.

${ }^{*} \mathrm{p}<0.01, \mathrm{tp}=0.03, \neq \mathrm{p}=0.04$.

$\mathrm{AM}$, arithmetic mean.tab

area $=0.71$ (95\% CI, 0.69 to 0.73$))$ and calibration of the model in the development set was 0.95. Model optimism was small (AUC difference was 0.01 ). The calibration plot showed a calibration slope of 0.80 ( $95 \% \mathrm{CI}, 0.65$ to 0.98$)$ in the validation set (figure 1B).

A sensitivity of $99 \%-100 \%$, a specificity of $96 \%-100 \%$, a PPV of $62 \%-66 \%$ and an NPV of $40 \%-44 \%$ were obtained for the developed model using a selected outpoint of $\geq 0.48$ derived from ROC curve. For models application in clinical practice, see online supplementary tables S3 and S4.

\section{Prediction of BA and BR using medical history}

Model development, validation and updating

Using a univariate analysis, the candidate predictors identified from the medical history were associated with the onset of BA and BR (table 4). Fitting a logistic regression model, three selected significant predictors $(\mathrm{p}<0.05)$ associated with the onset of BA. The ROC area of the developed model after bootstrapping was 0.85 (95\% CI, 0.78 to 0.88 ), and the calibration of the model in the development set was 0.96 (table 4). Again optimism was small (AUC difference was 0.02 ). Figure $1 \mathrm{C}$ shows the calibration plot of the model in the validation set with a slope of 0.82 (95\% CI, 0.60 to 1.04 ).
The model showed a sensitivity of $98 \%-100 \%$, a specificity of $99 \%-100 \%$, a PPV of $20 \%-30 \%$ and an NPV of $76 \%-80 \%$ using a selected outpoint of $\geq 0.10$ represented by the ROC curve.

The developed medical history model predicting BR included five selected significant predictors $(\mathrm{p}<0.05)$. The discrimination of the model was fair (ROC area $=0.74(95 \% \mathrm{CI}, 0.71$ to 0.75$)$ ) in the validation set and calibration was 0.97 in the development set (table 4). The optimism was small (AUC difference was 0.03). The calibration of model produced a calibration slope of 0.83 (95\% CI, 0.69 to 1.03 ) (figure 1D).

The model yielded a sensitivity of 99\%-100\%, a specificity of $99 \%-100 \%$, a PPV of $60 \%-64 \%$ and an NPV of $36 \%-40 \%$ using a selected outpoint of $\geq 0.47$ obtained by the ROC curve. For models' application in clinical practice, see online supplementary tables S5 and S6.

\section{DISCUSSION}

In a previously developed nationwide medical surveillance programme, Dutch bakery workers at high or intermediate risk for sensitisation to wheat, rye and/or $\alpha$-amylase were referred to a specialised clinic for a clinical work-up. ${ }^{13}$ This study investigated the possibility of prediction of occupational allergic 
Table 2 The health characteristics of the bakery workers based on a self-administered questionnaire and the medical history provided by a physician

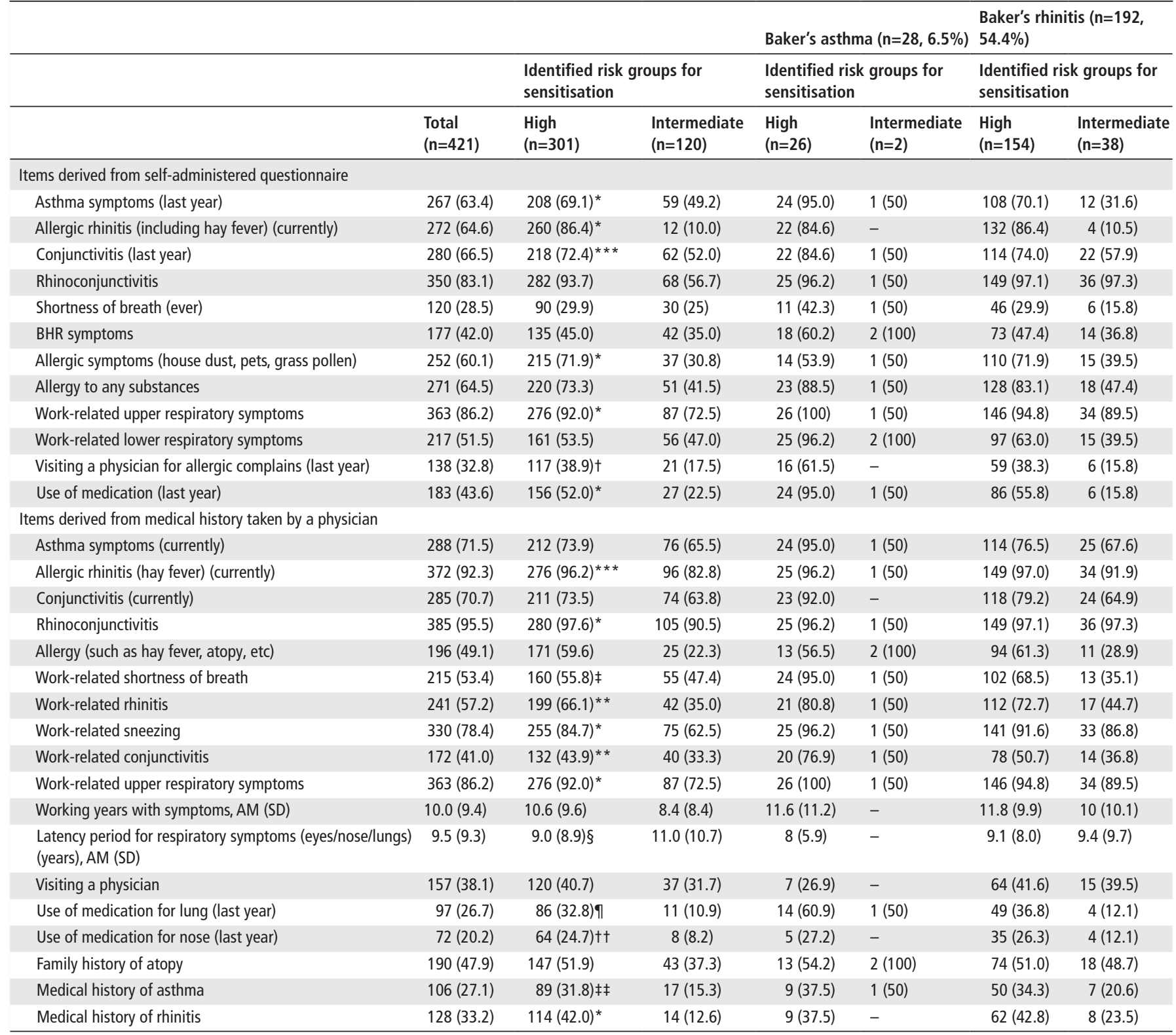

Data presented as $\mathrm{n}(\%)$ unless otherwise stated.

${ }^{*} \mathrm{p}<0.0001,{ }^{* *} \mathrm{p}=0.01,{ }^{* * *} \mathrm{p}=0.001, \mathrm{tp}=0.0004, \neq \mathrm{p}=0.09, \S \mathrm{p}=0.04,9 \mathrm{p}=0.0002,+\dagger \mathrm{p}=0.002, \neq \neq \mathrm{p}=0.03$ are significantly different from those baker workers identified as an intermediate-risk group.

AM, arithmetic mean; BHR, bronchial hyper-responsiveness.

asthma and rhinitis using two simple tools, namely a self-administered questionnaire and medical history taken by a physician. To the best of our knowledge, this has not been addressed in previous studies. The results demonstrated that the probability of onset of BA and BR in workers at risk of being sensitised can be estimated with the candidate items from both self-administered questionnaire and the medical history. The highly sensitive and specific developed models showed a relatively good discrimination and calibration. The results of the internal validity evaluation showed that the discriminations of the developed models in the validation set were satisfactory, and also the degree of the over-optimism of the developed models was very small. Calibration slopes were smaller than 1 (079-0.83).

The comparison of the selected items predicting BA and BR in the developed models of self-administered questionnaire and the medical history showed some similarities and differences. Both models predicting BA included predictors of work-related lower respiratory symptoms, allergy (work-related conjunctivitis reflecting allergy) and use of medication (as a strong predictor which might be indicative of disease severity). The predictor of use of medication in the questionnaire model is more sensitive than in the medical history model. In bakers with a low sensitisation probability, the reported rate of medication use was very low. ${ }^{10}$ Comparison of the selected items predicting BR in both developed models showed some similarities as well; both included work-related upper and lower respiratory symptoms, allergy and type of job. Small differences might be explained by the presence of non-identical items or clusters used in both developed models. The predictor of type of shift was 


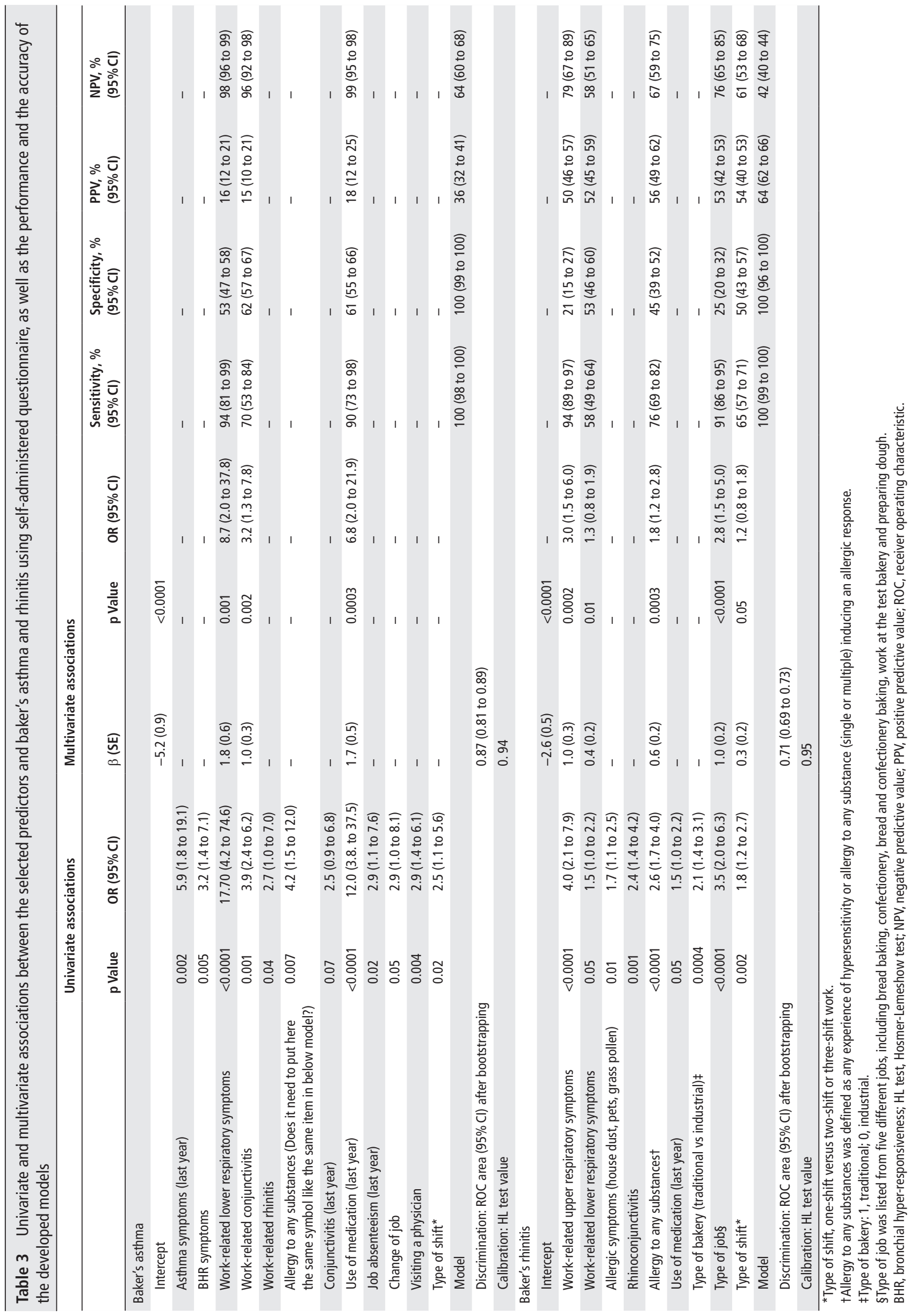



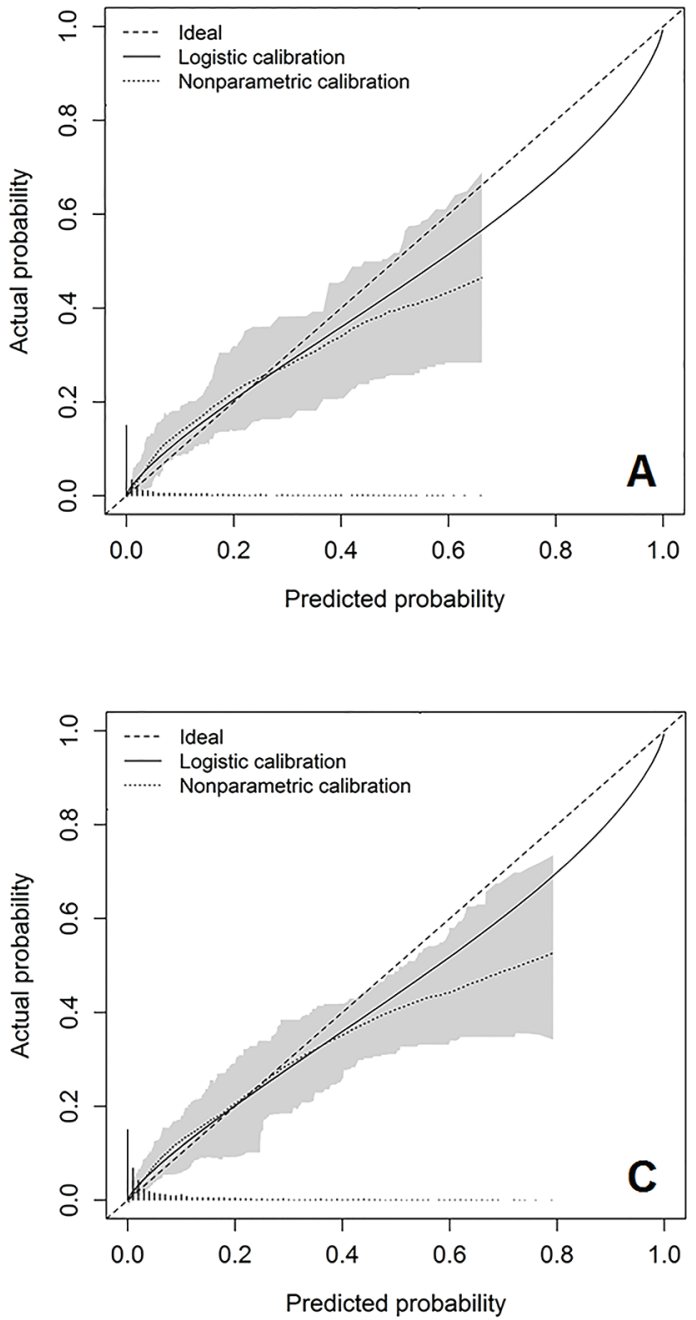
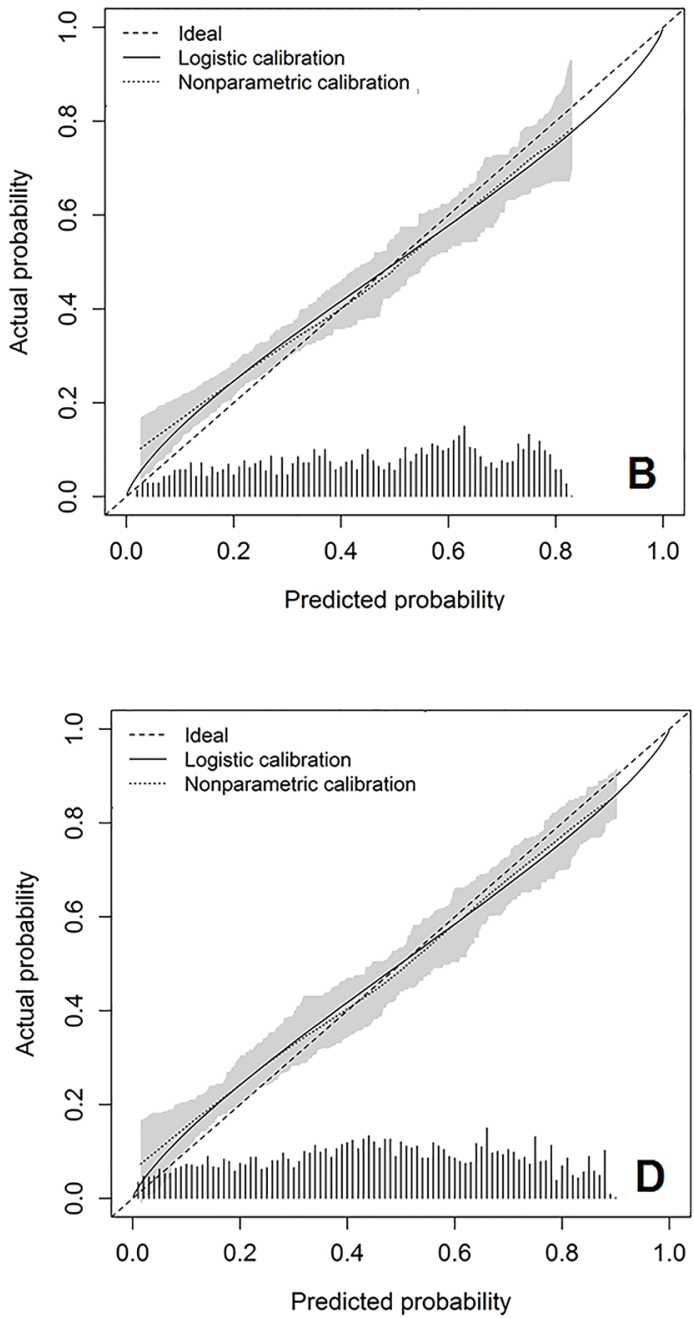

Figure 1 Calibration plots with empirical quintiles (the lower 2.5\% and upper 97.5\% quintiles) of the bootstrap distribution for the developed models of questionnaire and medical history predictive of baker's asthma and baker's rhinitis in the validation set: (A) the questionnaire model predictive of baker's asthma, $(B)$ the questionnaire model predictive of baker's rhinitis, $(C)$ the medical history model predictive of baker's asthma and (D) the medical history model predictive of baker's rhinitis. The dashed line is the ideal $45^{\circ}$ line reprehensive of a perfect calibration with an intercept 0 and a slope equal to 1 . The dotted line is a smoothed curve that displays a non-parametric estimate of the association between the predicted probability and the observed frequencies of the outcomes. The solid line indicates the logistic calibration. The vertical lines art the bottom exhibit the distribution of the predicted probabilities.

selected in the self-administered questionnaire-based model, and the predictor of working years with work-related symptoms was selected in the medical history-based model.

The developed models were highly sensitive and specific. A previous study in Dutch isocyanate-exposed workers showed a high sensitivity, but relatively low specificity of a respiratory questionnaire for identifying occupational asthma. ${ }^{24}$ In another study a low sensitivity was found for a questionnaire used to diagnose asthma among bakery and sandwich production workers. ${ }^{25}$ In our study, stratifying groups at high and intermediate risk of sensitisation increased the predicted probability of having $\mathrm{BA}$ and $\mathrm{BR}$.

From 28 workers with BA, 26 (93\%) came from the high-risk group, for BR this was 154 out of 192 workers (80\%). These findings suggest that priority should be given to high-risk groups for further clinical evaluation.

Our estimated PPV for BA was relatively low. This can most likely be explained by the relatively low prevalence of BA in the study population. PPV as the most important diagnostic measure of accuracy in predicting the probability of a disease is more influenced by the disease prevalence, whereas NPV is somewhat influenced weaker by the disease prevalence. ${ }^{26}$ Both estimated PPV and NPV predicting BA and BR cannot be generalised to other populations as the probability of a specific disease depends on the prevalence rate of disease in that population. ${ }^{27}$

In the current study, $93 \%$ of cases with BA also had BR, suggesting a strong link between the onsets of these two outcomes. This is in agreement with previous studies reporting a significant relationship between occupational asthma and rhinitis, particularly if HMW allergens and IgE-mediated mechanisms were involved. ${ }^{28-31}$ Occupational rhinitis may thus be a risk factor for developing occupational asthma and should be addressed with a high priority by physicians. ${ }^{31}$ Furthermore, the application of measures such as reducing or eliminating allergen exposure particularly in workers with BR will prevent new cases of BA and subsequently decrease the cost and disease burden. ${ }^{32}$

The comparison of discriminative ability of both models predicting BA indicates that both approaches were highly sensitive to identify workers with and without diagnosed BA. It may also show the importance of application of a simple questionnaire in the prediction of BA in bakery workers at high risk for sensitisation and should have immediate clinical assessments. 
Table 4 Univariate and multivariate associations between selected predictors and baker's asthma and rhinitis using the medical history items, as well as the performance and the accuracy of the developed models

\begin{tabular}{|c|c|c|c|c|c|c|c|c|c|}
\hline & \multicolumn{2}{|c|}{ Univariate associations } & \multicolumn{7}{|c|}{ Multivariate associations } \\
\hline & $\mathrm{p}$ Value & OR $(95 \% \mathrm{Cl})$ & $\beta$ (SE) & p Value & $\begin{array}{l}\text { OR } \\
(95 \% \mathrm{Cl})\end{array}$ & $\begin{array}{l}\text { Sensitivity, \% } \\
(95 \% \mathrm{CI})\end{array}$ & $\begin{array}{l}\text { Specificity, \% } \\
(95 \% \mathrm{Cl})\end{array}$ & $\begin{array}{l}\text { PPV, } \% \\
(95 \% \mathrm{Cl})\end{array}$ & $\begin{array}{l}\text { NPV, \% } \\
(95 \% \mathrm{Cl})\end{array}$ \\
\hline \multicolumn{10}{|l|}{ Baker's asthma } \\
\hline Intercept & & & $-4.6(0.8)$ & $<0.0001$ & & & & & \\
\hline Conjunctivitis & 0.03 & $3.7(1.1$ to 12.4$)$ & - & - & - & - & - & - & - \\
\hline Asthma symptoms & 0.005 & $7.2(1.8$ to 29.3$)$ & - & - & - & - & - & - & - \\
\hline Work-related conjunctivitis & 0.001 & $3.9(1.7$ to 9.0$)$ & $1.2(0.4)$ & 0.003 & $\begin{array}{l}3.5(1.4 \text { to } \\
8.5)\end{array}$ & 70 (53 to 84 ) & 62 (57 to 67$)$ & 15 (10 to 21$)$ & 96 (92 to 98 ) \\
\hline Work-related rhinitis & 0.04 & $2.7(1.0$ to 7.0$)$ & - & - & - & - & - & - & - \\
\hline Work-related dyspnoea & 0.0002 & 14.5 (3.6 to 58.9 ) & $1.8(0.6)$ & 0.004 & $\begin{array}{l}5.6(1.8 \text { to } \\
31.8)\end{array}$ & 93 (80 to 99$)$ & 49 (44 to 54$)$ & 16 (11 to 21$)$ & 99 (96 to 100$)$ \\
\hline Medical history of asthma & 0.02 & 2.3 (1.1 to 4.8$)$ & - & - & - & - & - & - & - \\
\hline $\begin{array}{l}\text { Use of medication for lungs } \\
\text { (last year) }\end{array}$ & $<0.0001$ & $5.9(27$ to 12.5$)$ & $1.2(0.3)$ & 0.001 & $\begin{array}{l}3.7(1.6 \text { to } \\
8.3)\end{array}$ & 60 (43 to 76$)$ & 79 (75 to 83$)$ & 22 (14 to 31$)$ & 95 (92 to 97$)$ \\
\hline Chang of job & 0.05 & $2.9(1.0$ to 8.1$)$ & - & - & - & - & - & - & - \\
\hline Job absenteeism (ever) & 0.004 & $4.4(1.6$ to 12.1$)$ & - & - & - & - & - & - & - \\
\hline $\begin{array}{l}\text { Working years with } \\
\text { symptoms ( } \geq 10 \text { years) }\end{array}$ & 0.002 & $1.0(1.0$ to 1.1$)$ & & & & & & & \\
\hline Model & & & & & & 100 (98 to 100$)$ & 100 (99 to 100$)$ & 26 (20 to 30$)$ & 78 (76 to 80$)$ \\
\hline $\begin{array}{l}\text { Discrimination: ROC area } \\
(95 \% \mathrm{Cl}) \text { after bootstrapping }\end{array}$ & & & $\begin{array}{l}0.85(0.78 \\
\text { to } 0.88)\end{array}$ & & & & & & \\
\hline Calibration: & & & 0.96 & & & & & & \\
\hline \multicolumn{10}{|l|}{$\mathrm{HL}$ test value } \\
\hline \multicolumn{10}{|l|}{ Baker's rhinitis } \\
\hline Intercept & & & $-2.9(0.5)$ & $<0.0001$ & & & & & \\
\hline $\begin{array}{l}\text { Allergy (such as hay fever, } \\
\text { atopy, etc) }\end{array}$ & 0.002 & 1.9 (1.2 to 2.8$)$ & $0.5(0.2)$ & 0.005 & $\begin{array}{l}1.5(1.0 \text { to } \\
2.3)\end{array}$ & 54 (47 to 61 ) & 56 (50 to 63 ) & 54 (476 to 62$)$ & 61 (54 to 68 ) \\
\hline Rhinoconjunctivitis & 0.008 & 15.4 (2.0 to 118.7$)$ & - & - & - & - & - & - & - \\
\hline $\begin{array}{l}\text { Work-related upper } \\
\text { respiratory symptoms }\end{array}$ & $<0.0001$ & 4.0 (2.0 to 7.9$)$ & $1.2(0.3)$ & $<0.0001$ & $\begin{array}{l}3.5(1.7 \text { to } \\
7.2)\end{array}$ & 91 (90 to 97 ) & 21 (16 to 27 ) & 52 (46 to 57 ) & 79 (67 to 89 ) \\
\hline Work-related dyspnoea & 0.003 & $1.8(1.2$ to 2.7$)$ & $0.5(0.2)$ & 0.002 & $\begin{array}{l}1.6(1.0 \text { to } \\
2.4)\end{array}$ & 60 (53 to 67$)$ & 52 (45 to 59$)$ & 54 (47 to 61$)$ & 60 (53 to 67$)$ \\
\hline $\begin{array}{l}\text { Working years with } \\
\text { symptoms ( } \geq 10 \text { years) }\end{array}$ & $<0.0001$ & $2.7(1.8$ to 4.0$)$ & $0.8(0.2)$ & $<0.0001$ & $\begin{array}{l}2.0(1.3 \text { to } \\
3.2)\end{array}$ & 51 (44 to 58 ) & 72 (66 to 78 ) & 62 (54 to 69$)$ & 52 (56 to 68 ) \\
\hline Medical history of asthma & 0.01 & $1.7(1.1$ to 2.7$)$ & - & - & - & - & - & - & - \\
\hline Medical history of rhinitis & 0.003 & $1.9(1.2$ to 2.9$)$ & - & - & - & - & - & - & - \\
\hline Use of medication for lungs & 0.02 & 1.7 (1.1 to 2.7$)$ & - & - & - & - & - & - & - \\
\hline Use of medication for nose & 0.04 & 1.7 (1.0 to 2.8$)$ & - & - & - & - & - & - & - \\
\hline Type of job* & $<0.0001$ & 3.5 (2.0 to 6.3$)$ & $1.0(0.2)$ & $<0.0001$ & $\begin{array}{l}3.0(1.6 \text { to } \\
5.8)\end{array}$ & 91 (86 to 96$)$ & 25 (20 to 32 ) & 55 (45 to 58$)$ & 76 (64 to 85 ) \\
\hline Model & & & & & & 100 (99 to 100$)$ & 100 (99 to 100$)$ & 62 (60 to 64$)$ & 38 (36 to 40$)$ \\
\hline $\begin{array}{l}\text { Discrimination: } \mathrm{ROC} \text { area } \\
(95 \% \mathrm{Cl}) \text { after bootstrapping }\end{array}$ & & & $\begin{array}{l}0.74(0.71 \\
\text { to } 0.76)\end{array}$ & & & & & & \\
\hline Calibration: HL test value & & & 0.97 & & & & & & \\
\hline
\end{tabular}

*Type of job was listed from five different jobs, including bread baking, confectionery, bread and confectionery baking, work at the test bakery and preparing dough.

HL test, Hosmer-Lemeshow test; NPV, negative predictive value; PPV, positive predictive value; ROC, receiver operating characteristic.

The obtained calibration slopes smaller than 1 in the validation set can be a result of the model developing in a relatively small dataset with a small number of events, which reflects that the predictions were too extreme: low prediction too low, and high predictions too high. ${ }^{33}$ It can also be interpreted as reflecting a need for shrinkage of regression coefficients in a prediction model, which will show a better calibration in new patients. ${ }^{34} 35$ Although calibration and discrimination are important in considering the full range of predicted risks in a prediction model, they do not assess clinical usefulness. ${ }^{34}$

This study confirms that our previously developed diagnostic model accurately predicts sensitisation to bakery allergens and hence can be used to select bakers for further medical evaluation. The major strength of the present study is that the models predicting allergy were developed in a population of bakers with an elevated risk for sensitisation to bakery allergens who were referred to a specialised clinic. In this selected group of bakers, occupational allergy could be predicted by a questionnaire-based diagnostic prediction model and a model based on medical history model. Thus, medical history models may support physicians during clinical assessment and during medical phone consultation in bakers at intermediate risk.

The present study had some limitations. First, recall bias of previous reported symptoms by subjects particularly in 
the self-administered questionnaire can lead to differential (non-random) misclassification. This distorts the measure of association between exposure and outcomes by any magnitude and direction, and this distortion may be difficult to predict. ${ }^{3637}$ Second, the high number of potential candidate predictors studied versus the insufficient number of cases with BA may interfere in the detection of significant predictors. As a consequence, this may affect the accuracy of the developed models. Since there is no exact rule for the estimation of sample size, a rule of thumb is that each candidate predictor requires at least 10 cases, as suggested by Harrell et al. ${ }^{38}$ Third, the use of bivariable selection (BVS) of candidate predictors yielded a potential bias due to the BVS method wrongly rejecting potentially important variables, and it is unable to control confounding or intercorrelations between independent variables. ${ }^{39}$ The fourth limitation of this study is the low PPVs and NPVs of some developed models predictive of BA and BR, which led to the decrease in the diagnostic accuracy and the clinical usefulness of those models for clinical/occupational health purposes. Future clinical studies with a large sample size of bakery workers may improve the accuracy of the developed models.

In the Netherlands, occupational asthma is not a compensable disease. Hence, the branch of traditional and industrial bakers developed a comprehensive programme including a good practice guide for bakeries with specific exposure measures and resources to facilitate task or job change in workers with BA.

In conclusion, we demonstrated that diagnostic prediction models provided simple tools to predict the onset of baker's asthma and rhinitis. Our results support the idea that the self-administered questionnaire models can be used to select bakers for further medical evaluation. Before the developed diagnostic prediction models can be used in medical practice further studies are needed to validate the predictive value of the models for occupational asthma and rhinitis in different populations exposed to bakery allergens (external validation) or other HMW allergens (generalisability). Furthermore, cost-effectiveness studies are needed to use these models as a general tool in medical triage of workers who are occupationally exposed to bakery allergens.

Acknowledgements The authors thank $T$ Rens of the branch of industry for supporting the surveillance programme, E M van Otterloo for information technology and database development, and B M Aalders de Ruijter and MM Niederer for lung function testing and logistics.

\section{Competing interests None declared.}

Ethics approval This study was conducted as usual medical care.

Provenance and peer review Not commissioned; externally peer reviewed

(c) Article author(s) (or their employer(s) unless otherwise stated in the text of the article) 2017. All rights reserved. No commercial use is permitted unless otherwise expressly granted.

\section{REFERENCES}

1 Brisman J, Järvholm B, Lillienberg L. Exposure-response relations for self reported asthma and rhinitis in bakers. Occup Environ Med 2000;57:335-40.

2 Brant A. Baker's asthma. Curr Opin Allergy Clin Immunol 2007;7:152-5.

3 Heederik D, Houba R. An exploratory quantitative risk assessment for high molecular weight sensitizers: wheat flour. Ann Occup Hyg 2001;45:175-85.

4 Baur X, Degens PO, Sander I. Baker's asthma: still among the most frequent occupational respiratory disorders. J Allergy Clin Immunol 1998;102:984-97.

5 Brisman J. Baker's asthma. Occup Environ Med 2002;59:498-502.

6 Baur X, Posch A. Characterized allergens causing bakers' asthma. Allergy 1998;53:562-6.

7 Mbatchou Ngahane BH, Afane Ze E, Nde F, et al. Prevalence and risk factors for allergic rhinitis in bakers in Douala, Cameroon. BMJ Open 2014;4:e005329.

8 Moscato G, Vandenplas O, Van Wijk RG, et al. European Academy of Allergology and Clinical Immunolgy. EAACI position paper on occupational rhinitis. Respir Res 2009; 10:16.
9 Baatjies R, Jeebhay MF. Baker's allergy and asthma asthma - a review of the literature: allergies in the workplace. Curr Allergy Clin Immuno/;26:232-43.

10 Meijer E, Suarthana E, Rooijackers J, et al. Application of a prediction model for workrelated sensitisation in bakery workers. Eur Respir J 2010;36:735-42.

11 Baur X, Sigsgaard T, Aasen TB, et al; ERS Task Force on the Management of Workrelated Asthma. Guidelines for the management of work-related asthma. Eur Respir J 2012;39:529-45.

12 Wilken D, Baur X, Barbinova L, et al; ERS Task Force on the Management of Workrelated Asthma. What are the benefits of medical screening and surveillance? Eur Respir Rev 2012:21:105-11.

13 Suarthana E, Vergouwe Y, Moons KG, et al. A diagnostic model for the detection of sensitization to wheat allergens was developed and validated in bakery workers. J Clin Epidemiol 2010;63:1011-9.

14 Doekes G, Douwes J, Wouters I, et al. Enzyme immunoassays for total and allergen specific lgE in population studies. Occup Environ Med 1996;53:63-70.

15 Pellegrino R, Viegi G, Brusasco V, et al. Interpretative strategies for lung function tests. Eur Respir J 2005;26:948-68.

16 Quanjer PH, Tammeling GJ, Cotes JE, et al. Lung volumes and forced ventilatory flows. Report working party standardization of lung function tests, European community for steel and coal. Official statement of the European Respiratory Society. Eur Respir J Supp/ 1993;16:5-40.

17 Crapo RO, Casaburi R, Coates AL, et al. Guidelines for methacholine and exercise challenge testing-1999. This official statement of the American Thoracic Society was adopted by the ATS board of directors, July 1999. Am J Respir Crit Care Med 2000;161:309-29.

18 Tarlo SM, Balmes J, Balkissoon R, et al. Diagnosis and management of workrelated asthma: American College of Chest Physicians consensus statement. Chest 2008;134(Suppl 3):S1-41.

19 van der Heijden GJ, Donders AR, Stijnen T, et al. Imputation of missing values is superior to complete case analysis and the missing-indicator method in multivariable diagnostic research: a clinical example. J Clin Epidemio/ 2006;59:1102-9.

20 Steyerberg EW, Harrell FE, Borsboom GJ, et al. Internal validation of predictive models: efficiency of some procedures for logistic regression analysis. J Clin Epidemiol 2001;54:774-81.

21 Steyerberg EW, Borsboom GJ, van Houwelingen HC, et al. Validation and updating of predictive logistic regression models: a study on sample size and shrinkage. Stat Med 2004;23:2567-86

22 Hosmer D, Lemeshow S. Applied logistic regression. New York: John Wiley and Sons, 1989.

23 Harrell FE, Lee KL, Mark DB. Multivariable prognostic models: issues in developing models, evaluating assumptions and adequacy, and measuring and reducing errors. Stat Med 1996;15:361-87.

24 Kraw M, Tarlo SM. Isocyanate medical surveillance: respiratory referrals from a foam manufacturing plant over a five-year period. Am J Ind Med 1999;35:87-91.

25 Gordon SB, Curran AD, Murphy J, et al. Screening questionnaires for bakers' asthmaare they worth the effort? Occup Med 1997;47:361-6.

26 Šimundić AM. Measures of diagnostic accuracy: basic definitions. EJIFCC 2009;19:203-11.

27 Akobeng AK. Understanding diagnostic tests 1: sensitivity, specificity and predictive values. Acta Paediatr 2007;96:338-41.

28 Storaas T, Steinsvåg SK, Florvaag E, et al. Occupational rhinitis: diagnostic criteria, relation to lower airway symptoms and IgE sensitization in bakery workers. Acta Otolaryngol 2005; 125:1211-7.

29 Malo JL, Lemière C, Desjardins A, et al. Prevalence and intensity of rhinoconjunctivitis in subjects with occupational asthma. Eur Respir J 1997;10:1513-5.

30 Ameille J, Hamelin K, Andujar P, et al; Members of the RNV3P. Occupational asthma and occupational rhinitis: the united airways disease model revisited. Occup Environ Med 2013;70:471-5.

31 Stevens WW. Grammer LC 3rd Occupational rhinitis: an update. Curr Allergy Asthma Rep 2015;15:487.

32 Piirilä P, Estlander T, Hytönen $M$, et al. Rhinitis caused by ninhydrin develops into occupational asthma. Eur Respir J 1997;10:1918-21.

33 Steyerberg EW, Vergouwe Y. Towards better clinical prediction models: seven steps for development and an ABCD for validation. Eur Heart J 2014;35:1925-31.

34 Steyerberg EW, Vickers AJ, Cook NR, et al. Assessing the performance of prediction models: a framework for traditional and novel measures. Epidemiology 2010;21:128-38

35 Steyerberg EW, Eijkemans MJ, Harrell FE, et al. Prognostic modeling with logistic regression analysis: in search of a sensible strategy in small data sets. Med Decis Making 2001;21:45-56.

36 Infante-Rivard C, Jacques L. Empirical study of parental recall bias. Am J Epidemiol 2000;152:480-6

37 Hassan ES. Recall bias can be a threat to retrospective and prospective research designs. Internet J Epidemiol 2006;3:4.

38 Harrell FE, Lee KL, Califf RM, et al. Regression modelling strategies for improved prognostic prediction. Stat Med 1984;3:143-52.

39 Sun GW, Shook TL, Kay GL. Inappropriate use of bivariable analysis to screen risk factors for use in multivariable analysis. J Clin Epidemiol 1996;49:907-16. 


\section{Predicting occupational asthma and rhinitis in bakery workers referred for clinical evaluation}

Badri Sadat Jonaid, Jos Rooyackers, Erik Stigter, Lützen Portengen, Esmeralda Krop and Dick Heederik

Occup Environ Med2017 74: 564-572 originally published online March 17,2017

doi: 10.1136/oemed-2016-103934

Updated information and services can be found at:

http://oem.bmj.com/content/74/8/564

These include:

References This article cites 37 articles, 9 of which you can access for free at: http://oem.bmj.com/content/74/8/564\#ref-list-1

Email alerting Receive free email alerts when new articles cite this article. Sign up in the service box at the top right corner of the online article.

\section{Notes}

To request permissions go to:

http://group.bmj.com/group/rights-licensing/permissions

To order reprints go to:

http://journals.bmj.com/cgi/reprintform

To subscribe to BMJ go to:

http://group.bmj.com/subscribe/ 